\title{
Nanocentric Plant Health Management with Special Reference to Silver
}

\author{
Pranab Dutta* and P.K. Kaman \\ Department of Plant Pathology, Assam Agricultural University, Jorhat-785013, Assam, India \\ *Corresponding author
}

\section{A B S T R A C T}

The term 'nano' (Greek word) mean dwarf. Nanometre ( $\mathrm{nm}$ ) is one-billionth of a metre, or approximately one hundred thousandth of the width of a human hair. Nanotechnology, the fascinating science refers to the technology of rearranging and processing of atoms and molecules to fabricate materials to nano specifications such as a nanometre $(1-100 \mathrm{~nm})$. A key requirement in the area of nanotechnology is the growth of reliable and environment friendly process for synthesis of metallic nanoparticles. Synthesis and characterization of noble metal nanoparticle like silver with unique electronics, optical, magnetic and chemical properties, which differ considerably from those of the corresponding bulk material is a challenge and are technological importance. In our study we synthesized silver nanoparticle from different potential biological sources, which were characterized by UV-VIS spectrophotometer, DLS, XRD, TEM and Zeta potential. The green synthesized silver nanoparticle when tested against different plant pathogens like, Rhizoctonia solani, Sclerotium rolfsii, Fusarium spp., Sclerotinia sclerotiorum, and Colletotrichum capsici, we found silver nanoparticle at $100 \mathrm{ppm}$ have higher antifungal efficacy as compared to the recommended chemical. In our laboratory, works on green synthesis of nanoparticle like zinc oxide, copper, gold and chitosan, their efficacy against different plant pathogens and preparation of nanobioformulation is in progress. If these are found effective it will pave the way of using green synthesized nano particle for plant disease management. This will also reduce the pressure of pesticide load in the environment to the extent of many fold. Scientists have developed interest towards exploring new applications of nanotechnology in agriculture and the food industry too- if these discoveries applied wisely, the environment, the agricultural sector and the food industry will indeed see remarkable change for the superior in the forth coming years.

\section{Introduction}

The art and science of nanotechnology involves designing, characterization, production and application of structures, devices and systems by controlling shape and size of the nanoscale. It deals with the creation of useful materials, devices and systems using the particles of nanometer length scale and exploitation of novel properties (physical, chemical, biological) at that length scale. The field of nanotechnology opens up novel applications in agriculture. One such applications is to control the plant pathogens which reduces the agricultural production worldwide due to plant diseases every year. Nanotechnological application in plant pathology is still at nascent stage. Remote activation and monitoring of intelligent nano delivery systems can 
minimize the use of fungicides and pesticides in future. Studies have confirmed that metal nanoparticles are effective against plant pathogens, insects and pests (Choudhury et al., 2010). For example, eco-friendly fungicides with nanopesticides are being developed to utilize its implication its pathogen-killing properties only when it is inside the targeted pathogen (Liu, 2006). However the implication of nanoparticles in disease management at field level and their antimicrobial mechanisms and toxicity on plant ecosystem is yet to be known (Alghuthaym et al., 2015).

Recent studies have demonstrated antimicrobial activities of various nanoparticle materials, including silver, copper, titanium dioxide and zinc oxide. The use of nanoparticles (NPs) of silver and zinc oxide has been seen as a viable solution to stop infectious diseases due to the antimicrobial properties of these NPs.

\section{Properties of nanoparticles}

The intrinsic properties of metal nanoparticles are mainly determined by size, shape, composition, crystallinity and morphology. At the nanoscale, the physical, chemical, and biological properties of materials differ in fundamental and valuable ways from the properties of individual atoms and molecules or bulk matter. Some of these properties arehigh surface area to volume ratio, greater specific surface area lead to increase rate of absorption, high stability in ambient temperature, UV light, high mobility due to their smaller size, optical properties.

\section{Silver nanoparticles}

Silver nano particle are also considered as the most studied and utilized nano particle for bio-system. It has long been known to have antimicrobial activities. Silver nanoparticles, which have a high surface area and high fraction of surface atoms, have high antimicrobial effect as compared to the bulk silver. Nano silver colloid is a well dispersed and stabilized silver nano particle solution and is more adhesive on bacteria and fungus, hence are better fungicide and bactericide. Silver is known as a powerful disinfecting agent. It kills unicellular microorganisms by inactivating enzymes having metabolic functions in the microorganisms by oligodynamic action. Silver in an ionic state exhibits high antimicrobial activity (Thomas and McCubin, 2003) (Table 3). However, ionic silver is unstable due to its high reactivity and thus gets easily oxidized or reduced into a metal depending on the surrounding media and it does not continuously exert antimicrobial activity.

\section{Why silver?}

Silver in any form is not thought to be toxic to the immune, cardiovascular, nervous or reproductive system and it is not considered to be carcinogenic, therefore silver is relatively non-toxic (Chen, 2008). Moreover in agriculture it can curb the plant pathogens at low dose as compared to chemicals which in turn reduce the cost of cultivation as well as keep the environment healthy.

\section{Synthesis of Ag nanoparticle}

Recently, nanoparticle synthesis is among the most interesting scientific areas of inquiry. Several physical and chemical methods have been used for synthesizing and stabilizing silver nanoparticles (Klaus et al., 1991 and Senapati, 2005). Chemicals methods including chemical reduction using a variety of organic and inorganic reducing agents, electrochemical reduction, physicochemical reduction, and radiolysis and physical methods including ultraviolet and microwave radiation, spark discharging, cryo-milling are 
widely used for the synthesis of silver nanoparticles. But these methods are associated with hazards and toxicity of chemicals and now therefore, it has become necessary to search for an alternative environmentally benign, simple, reproducible, reliable, low cost method which is based on the reducing capacity of some compound from natural flora and fauna.

\section{Synthesis of silver nanoparticles by microbes}

The synthesis of nanoparticle from microbes is known as the green approach of obtaining the nanoparticles. The synthesis of nanoparticles by microbes is relatively a simple process which can be carried out with nutritional media and apparatus used regularly in a microbiology laboratory. In order to isolate microbes that are tolerant/ resistant to metals and can synthesis nanomaterials preferably soils from mining sites, sea-beds, etc. can be screened using the enrichment and isolation methods. Figure 1 depicts the protocol of typical microbial synthesis of nanomaterials.

\section{Fungi as a source of silver nanoparticle}

Out of the different microbes, fungi can produce larger amounts of nanoparticles because they can produce high amount of mycelia mat and secrete larger amounts of proteins which directly translate to higher productivity of nanoparticles (Mohanpuria et al., 2008). The mechanism of silver nanoparticles production by fungi is said to follow the following steps:

Trapping of $\mathrm{Ag}+$ ions at the surface of the fungal cells and the subsequent reduction of the silver ions by the enzymes present in the fungal system (Mukherjee et al., 2001). The extracellular enzymes like naphthoquinones and anthraquinones are said to facilitate the reduction. It is also believed that the NADPH- dependent nitrate reductase and a shuttle quinine extracellular process are responsible for nanoparticles formation (Ahmd et al., 2003) from Fusarium oxysporum. But, the exact mechanism involved in silver nanoparticles production by fungi is not fully deciphered yet.

Some examples of fungal species that are already used by scientists as a source $\mathrm{Ag}$ nanoparticle are listed in table 1.

\section{Bacteria as a source of silver nanoparticles}

The first evidence of bacteria synthesizing silver nanoparticles was established using the Pseudomonas stutzeri AG259 strain that was isolated from silver mine (Haefeli et al., 1984). There are some microorganisms that can survive metal ion concentrations and can also grow under those conditions, and this phenomenon is due to their resistance to that metal.

The mechanisms involved in the resistance are efflux systems, alteration of solubility and toxicity via reduction or oxidation, biosorption, bioaccumulation, extracellular complex formation or precipitation of metals, and lack of specific metal transport systems (Husseiny et al., 2006). There is also another aspect that though these organisms can grow at lower concentrations, their exposure to higher concentrations of metal ions can induce toxicity. But, the most widely accepted mechanism of Ag biosynthesis is the presence of the nitrate reductase enzyme.

The enzyme converts nitrate into nitrite. In in vitro synthesis of $\mathrm{Ag}$ using bacteria, the presence of alpha-nicotinamide adenine dinucleotide phosphate reduced form (NADPH) - dependent nitrate reductase would remove the downstream processing step that is required in other cases (Vaidyanathan et al., 2010). 
Synthesis of silver nanoparticles from plant extracts

The use of plant extracts to synthesize silver nanoparticles a good option. The major advantage is that they are easily available, safe, and nontoxic in most cases, have a broad variety of metabolites that can aid in the reduction of $\mathrm{Ag}$ ions, and are quicker than microbes in the synthesis. The main mechanism considered for the process is plant-assisted reduction due to phytochemicals. The main phytochemicals involved are terpenoids, flavones, ketones, aldehydes, amides, and carboxylic acids. Flavones, organic acids, and quinones are water-soluble phytochemicals that are responsible for the immediate reduction of the ions. Studies have revealed that xerophytes contain emodin, an anthraquinone that undergoes tautomerization, leading to the formation of the silver nanoparticles. In the case of mesophytes, it was found that they contain three types of benzoquinones: cyperoquinone, dietchequinone and remirin. It was suggested that the phytochemicals are involved directly in the reduction of the ions and formation of silver nanoparticles (Jha et al., 2009). A number of plants having medicinal properties were successfully exploited for synthesis of silver nanooparticle in different parts of the world (Table 2).

Fig.1 Typical flowchart for microbial nanoparticle synthesis

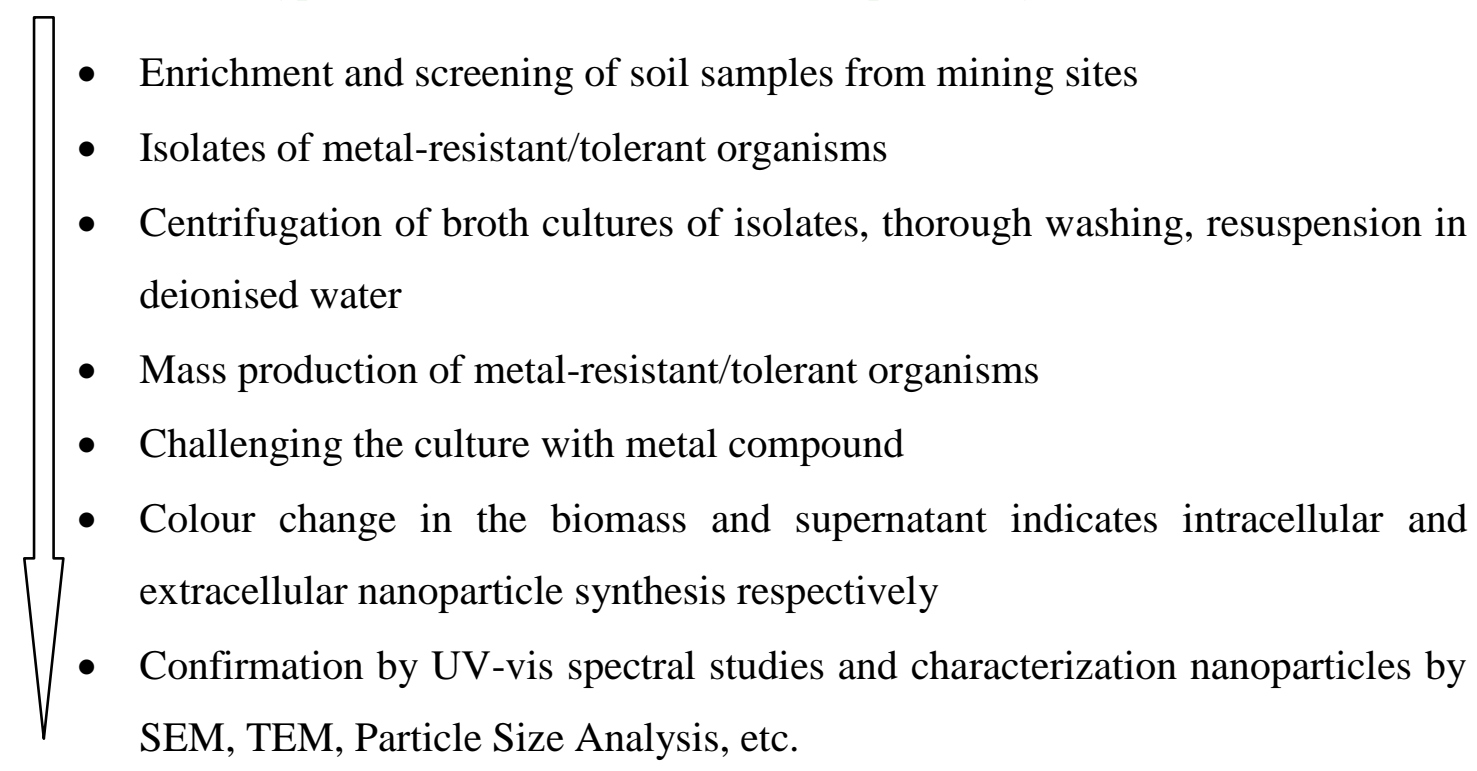

The nanoparticle synthesis mechanisms of unicellular and multicellular organisms may differ, however, the actual mechanisms are yet only laid down as hypothesis.

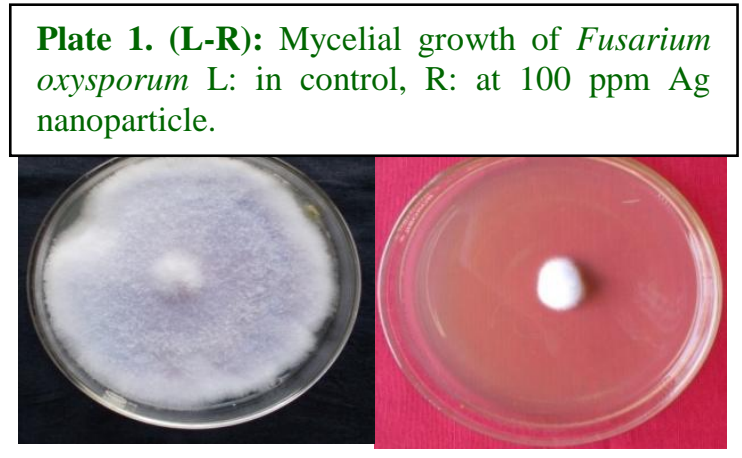


Table.1 Fungi that synthesize silver nanoparticles or other metallic nanostructures

\begin{tabular}{|l|l|l|}
\hline Fungi & Mode of Synthesis & References \\
\hline Fusarium oxysporum & Extracellular & Duran et al., (2005) \\
\hline Aspergillus niger & Extracellular & Gade et al., (2008) \\
\hline Fusarium acuminatum & Extracellular & Ingle et al., (2008) \\
\hline Trichoderma asperellum & Extracellular & Mukherjee et al., (2008) \\
\hline Penicillium sp. & Extracellular & Sadowski et al., (2008) \\
\hline Phoma glomerata & Extracellular & Birla et al., (2009) \\
\hline Fusarium solani & Extracellular & Ingle et al., (2009) \\
\hline Fusarium semitectum & Extracellular & Basavaraja et al., (2007) \\
\hline Phoma sp. 3.2883 & Extracellular & Chen et al., (2003) \\
\hline Fusarium oxysporum & Extracellular & Krishnakumar et al., (2015) \\
\hline
\end{tabular}

Table.2 Silver nano particles synthesized from medicinal plants and their reported activity

\begin{tabular}{|c|c|c|c|c|c|}
\hline $\begin{array}{l}\text { SI } \\
\text { No }\end{array}$ & Name of the plants & $\begin{array}{l}\text { AgNO3 Concentration } \\
\text { Mode and time of } \\
\text { plant extraction }\end{array}$ & $\begin{array}{l}\text { Part } \\
\text { used }\end{array}$ & Activity & Reference \\
\hline 1 & Acalypha indica & $1 \mathrm{mM}$ Boiling $5 \mathrm{~min}$ & Leaf & Antifungal & $\begin{array}{l}\text { Krishnaraj et } \\
\text { al., } 2012\end{array}$ \\
\hline 2 & Allium sativum & $1 \mathrm{mM}$ Boiling $5 \mathrm{~min}$ & Clove & Antimicrobial & $\begin{array}{ll}\text { Ahmad } & \text { et } \\
\text { al., } 2011\end{array}$ \\
\hline 3 & Azadirachta indica & $10 \mathrm{mM} 30-240 \mathrm{~min}$ & Leaf & Antimicrobial & $\begin{array}{ll}\text { Prathana } & e t \\
\text { al., } 2011\end{array}$ \\
\hline 4 & Citrus sinensis & $1 \mathrm{mM}$ Boiling $2 \mathrm{~min}$ & Peel & Antibacterial & $\begin{array}{l}\text { Kaviya } \\
\text { al., } 2011\end{array}$ \\
\hline 5 & Cynodon dactylon & $1 \mathrm{mM}$ Boiling 2-3 min & Leaf & Antibacterial & $\begin{array}{l}\text { Sahu et al., } \\
2012\end{array}$ \\
\hline 6 & Mangifera indica & $0.1 \mathrm{mM}$ Boiling $1 \mathrm{~min}$ & Leaf & Antimicrobial & Philip, 2011 \\
\hline 7 & Medicago sativa & $1 \mathrm{mM}$ Soaking $10 \mathrm{mM}$ & Seed & Antibacterial & $\begin{array}{l}\text { Inbathamizh, } \\
\text { et al., } 2013\end{array}$ \\
\hline 8 & Murraya koenigii & $1 \mathrm{mM}$ Boiling 2-3 min & Leaf & Antimicrobial & $\begin{array}{l}\text { Lukman } \\
\text { al., } 2011\end{array}$ \\
\hline 9 & Piper betle $\mathrm{L}$. & $1 \mathrm{mM}$ Boiling $5 \mathrm{~min}$ & Leaf & Antimicrobial & $\begin{array}{l}\text { Usha et al., } \\
2011\end{array}$ \\
\hline 10 & Terminalia chebula & $10 \mathrm{mM} 50^{\circ} \mathrm{C}, 2 \mathrm{~min}$ & Fruit & Antimicrobial & $\begin{array}{l}\text { Jebakumar } \\
\text { et al., } 2012\end{array}$ \\
\hline
\end{tabular}


Table.3 Examples of antimicrobial activity of silver nanoparticle against various plant pathogens

\begin{tabular}{|l|l|l|}
\hline $\begin{array}{l}\text { Source/mode of synthesis of silver nanoparticles used } \\
\text { in the study }\end{array}$ & Target pathogen & References \\
\hline $\begin{array}{l}\text { Nanosized silver-chitosan composite prepared using } \\
\text { chitosan extracted from Aspergillus niger and silver } \\
\text { nanoparticles (Sigma-Aldrich, St. Louis, MO, USA) } \\
\text { according to the method described by Rhim } \text { et al., (2006) }\end{array}$ & Gray mold in strawberry & Moussa et al., (2013) \\
\hline $\begin{array}{l}\text { Colloidal solution of AgNPs provided by BioPlus Co. Ltd. } \\
\text { (Pohang, Korea) }\end{array}$ & $\begin{array}{l}\text { Various plant pathogenic } \\
\text { fungi }\end{array}$ & Kim et al., (2012) \\
\hline $\begin{array}{l}\text { Nanosized Ag-silica hybrid complex prepared by } \gamma \text { - } \\
\text { irradiation }\end{array}$ & $\begin{array}{l}\text { Pseudomonas syringae pv. } \\
\text { tomato }\end{array}$ & Chu et al., (2012) \\
\hline $\begin{array}{l}\text { Colloidal solution of AgNPs provided by BioPlus Co. } \\
\text { (Pohang, Korea) }\end{array}$ & Colletotrichum sp. & Lamsal et al., (2011a) \\
\hline $\begin{array}{l}\text { AgNPs provided by BioPlus Co. Ltd. (Pohang, Korea) } \\
\text { Silver nanoparticles synthesized using high-voltage arc } \\
\text { discharge method }\end{array}$ & $\begin{array}{l}\text { Powdery mildews on } \\
\text { cucumber and pumpkins }\end{array}$ & Lamsal et al., (2011b) \\
\hline AgNPs provided by Quantum Sphere Inc., Santa Ana, CA & $\begin{array}{l}\text { Bipolaris sorokiniana and } \\
\text { Magnaporthe grisea }\end{array}$ & Jo et al., (2009) \\
\hline AgNPs provided by BioPlus Co., Ltd & $\begin{array}{l}\text { Oak wilt pathogen } \text { Raffaelea } \\
\text { sp. }\end{array}$ & Kim et al., (2007) \\
\hline $\begin{array}{l}\text { Nanosilver (Shanghai Huzheng Nano Technology Co. } \\
\text { Ltd., China) }\end{array}$ & $\begin{array}{l}\text { Stem-end bacteria on cut } \\
\text { gerbera }\end{array}$ & Liu et al., (2009) \\
\hline $\begin{array}{l}\text { The nanosized silica-silver prepared by combining } \\
\text { nanosilver with silica molecules and water-soluble } \\
\text { polymer and exposing a solution including silver salt, } \\
\text { silicate, and water-soluble polymer to radioactive rays }\end{array}$ & $\begin{array}{l}\text { Powdery mildews of } \\
\text { pumpkin }\end{array}$ & Park et al., (2006) \\
\hline
\end{tabular}

Fig.2 Centrifuge tube containing the
extracellular filtrate of the T. asperallum in
aqueous solution of $1 \mathrm{~m} \mathrm{M} \mathrm{AgNO3} \mathrm{at} \mathrm{the}$
beginning of the reaction (A) and after $72 \mathrm{hrs}$ of
reaction (B)

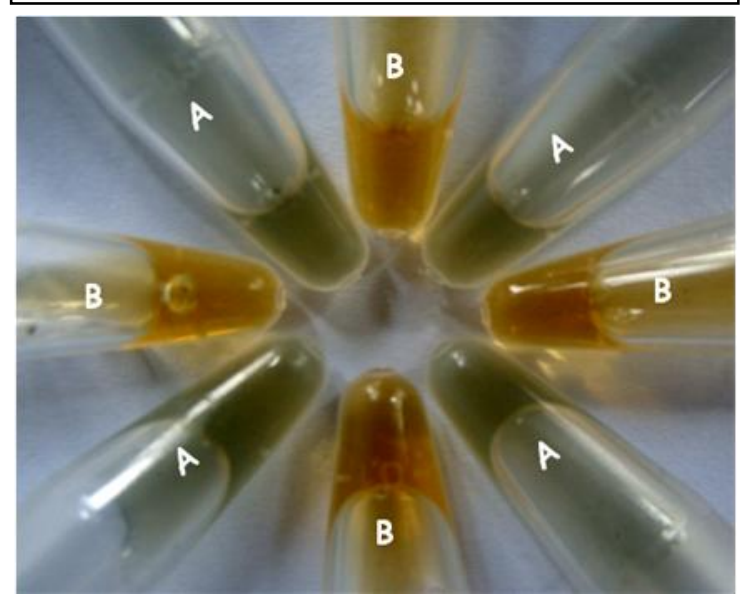


Use of Ag nanoparticle for better plant health management

The studies on the applicability of silver naoparticle for controlling plant diseases has been limited till date (Lamsal et al., 2011). Silver nanoparticles, which have a high surface area and high fraction of surface atoms, have high antimicrobial effect as compared to the bulk silver. Several members of plant pathogenic fungi belonging to ascomycetes and basidiomycetes develop sclerotia, including Sclerotinia sclerotiorum, S. minor, and Rhizoctonia solani. Sclerotia forming pathogens are widespread in the world and cause many important diseases in a wide host range of plants. Diverse disease management strategies, including chemical, physical, biological, cultural methods and genetic controls has been used to curb the diseases caused by sclerotiumforming fungi. However, their broad host range and the formation of sclerotia as survival structure make it difficult to control diseases caused by them. Not much is known about the effects of silver on phytopathogenic fungi as most studies have focused on bacterial and viral pathogens of animals. The field study has suggested that, the efficacy of silver is greatly influenced by application time and preventive applications of silver nanoparticles work better before fungal inoculam penetrate and colonize the plant tissue (Lamsal et al., 2011). The study on antifungal activity of silver nanoparticles suggested that nanometer-sized silver possesses different properties, which might come from morphological and structural (Changes (Nel et al., 2003). It was also shown that very minute quantities of nano- particles efficiently penetrate into the microbial cells, which implies that lower concentrations of nano-sized silvers would be sufficient for microbial control. It would be effective especially for some organisms that are less sensitive to antibiotics due to the poor penetration of some antibiotics into cells. A previous study showed that silver nanoparticles disrupt transport systems, including ion efflux (Morones et al., 2005). The dysfunction of ion efflux can cause rapid accumulation of silver ions, interrupting cellular processes at their lower concentrations such as metabolism and respiration by reacting with molecules. Also, silver ions are known to produce reactive oxygen species (ROS) via their reaction with oxygen, which are detrimental to cells, causing damage to proteins, lipids, and nucleic acids (Hwang et al., 2008). Many studies have shown a high inhibition effect at $100 \mathrm{ppm}$ concentration of silver nanoparticles. In most cases, inhibition increases as the concentration of silver nanoparticles is increased. It happens due to the high density at which the applied nanoparticle solution was able to saturate and cohere to fungal hyphae. Thus deactivate plant pathogenic fungi. Upon treatment with silver, DNA loses its ability to replicate, resulting in inactivated expression of ribosomal subunit proteins, as well as certain other cellular proteins and enzymes essential for ATP production. It has also been hypothesized that $\mathrm{Ag}+$ primarily affects the function of membrane-bound enzymes, such as those in the respiratory chain (Kim et al., 2012). But the mechanisms behind the activity of nano silver on bacteria are not yet fully known. The three most common mechanisms of toxicity proposed up till now are, 1) uptake of free silver ions followed by disruption in ATP production and DNA replication, 2) formation of Reactive Oxygen Species (ROS) and 3) direct damage to cell membranes.

\section{Works on silver nanoparticle at Assam Agricultural University}

In the nanotech laboratory of Department of Plant Pathology, AAU silver nanoparticles from biocontrol agents were synthesized (Trichoderma asperallum) (Fig. 2) and plant extracts. The biosynthesized silver nanoparticles were characterized by UV-Vis spectrophotometer, Dynamic Light Scattering (DLS), X-ray diffraction (XRD), Zeta Sizer and Transmission Electron Microscope (TEM). UV Vis spectrum of aqueous medium containing silver ion showed a peak at a wavelength of 420 $\mathrm{nm}$ corresponding to Plasmon Absorption of silver nanoparticle. By DLS study size of the biosynthesized silver nanoparticles was found 
as $27.64 \mathrm{~nm}$ with polydispersity index (PDI) of 0.409. This indicates that the biosynthesized nanoparticle were polydispersed in nature. The charge of silver nanoparticles was determined by zeta sizer and found to have negative potential value of -1.34 and it indicates formation of stable nanoparticle. TEM study revealed the formation well dispersed silver nanoparticles in the range of 9-41 nm with roughly spherical shape. Fungicidal activity of silver nanoparticle at different concentration (100 ppm, $50 \mathrm{ppm}, 30 \mathrm{ppm}$, and $10 \mathrm{ppm}$ ) was tested against four soil borne plant pathogens viz., Rhizoctonia solani, Fusarium spp., Sclerotinia sclerotiorum, and Sclerotium rolfsii and comparison was made with Carbendazim @3000 ppm. The result showed that the silver nanoparticles at $100 \mathrm{ppm}$ significantly inhibit the mycelial growth of the pathogens as compared to Carbendazim at $3000 \mathrm{ppm}$. But when the efficacy of $\mathrm{Ag}$ nanoparticle as seed treatments was tested on growth parameters of four different crop plants at different concentrations, we found increased growth parameters(root and shoot length, fresh and dry weight of chilli, french bean, and mustard) up to 100 ppm concentration. Further studies on effect of Ag nanoparticle on morphophysiology of plants and its effect on biochemical defense mechanism are in progress.

Similarly, in a PhD Programme, silver nanoparticles were synthesized from certain botanicals and when tested in vitro, it was found to be effective against lepidopteran pests of agricultural crops. During a study on efficacy of biosynthesized silver nanoaparticle from leaf of Parkia roxiburghii (Vedailata in Assamese) showed inhibitory to human pathogen like Staphylococcus aureus, Eschercia coli, Bacillus cereus and Aspergillus niger.

In conclusion, the use of Ag nanoparticle will not only reduce the fungal pathogen but also there are more possibilities of using in the management of bacterial plant and human pathogens. Further, as we observed it can also be used for enhancing seed germination and increasing the growth parameters of plants. Use of silver nanoparticle as plant protection material will definitely reduce the environmental hazard that occurs due to indiscriminate use of chemical pesticides. But before its wide spread use, the ecological issues need to be taken up with a greater effort to identify its effect on the environment.

\section{Acknowledgement}

The authors acknowledge the constructive suggestions and guidance received from Dr. D. K Bora, Dean, Faculty of Agriculture, AAU, Jorhat, Assam. The author also acknowledges the help of Dr. D.K. Sarma, Principal Scientist, Department of Plant Pathology, AAU, Jorhat, Assam during preparation of the article.

\section{References}

Ahmad, A., Mukherjee, P., Senapati, S., Mandal, D., Khan, M.I., Kumar, R. and Sastry M. (2003). Extracellular biosynthesis of silver nanoparticles using the fungus Fusarium oxysporum. Colloids and Surfaces B: Biointerfaces 28: 313318.

Ahmad, M; Khana, M.A;.Siddiqui, M.K.J; Salhi, M.Sand Alrokayan, S.A. (2011).Green synthesis, characterization and evaluation of biocompatibility of silver nanoparticles. Physica Electronica. 43:1266-1271.

Alghuthaymi, A.M., Almoammar, H., Rai, M., Galiev, S.E. and Elsalam, A. A. K. (2015). Myconanoparticles: synthesis and their role in phytopathogens management. Biotechnology \& Biotechnological Equipment 29(2): 221-236.

Chen, J.C., Liu, Z.H. and Ma, X. X (2003) Evidence of the production of silver nanoparticles via pretreatment of Phoma sp. 3.2882 with silver nitrate. Letter of Applied Microbiology. 37. 105-108.

Choudhury, S.R., Nair, K., Kumar, R., Gogoi, R., Srivastava, C., Gopal, M., Subhramanyam, B.S., Devakumar, C. and Goswami, A. (2010). Nanosulfur: a potent 
fungicide against food pathogen, Aspergillus niger. American Institute of Physics 12(76): 154-157.

Chu, H., Kim, H.J., Kim, J.S,; Kim, M.S., Park, H.J., and Kim, C.Y. (2012) A nanosized Ag-silica hybrid complex prepared by $\gamma$ irradiation activates the defense response in Arabidopsis. Radiation Physics Chemistry 81: 180-184

Haefeli, C., Franklin, C. and Hardy, K. (1984). Plasmid-determined silver resistance in Pseudomonas stutzeri isolated from a silver mine. Journal of Bacterioliology 158: 389-392.

Husseiny, M., Aziz, M.A.E.B.Y. and Mahmoud, M.A. (2006). Biosynthesis of gold nanoparticles using Pseudomonas aeruginosa. Spectrochimica Acta 67: 1003-1006.

Hwang, E.T., Lee, J.H.Y.J., Chae, Y.S.K., Kim, B.C., Sang, B.I. and Gu, M.B. (2008). Analysis of the toxic mode of action of silver nanoparticles using stress- specific bioluminescent bacteria. Small 4(7): 4650 .

Jebakumar, I.E.T. and Sethuraman, M. G. (2012)Instant green synthesis of silver nanoparticles using Terminalia chebula fruit extract and evaluation of their catalytic activity on reduction of methylene blue. Process Biochemistry. 47:1351-1357.

Jha, A., Prasad, K., Prasad, K. and Kulkarni, A.R. (2009). Plant system: nature's nanofactory. Colloids Surafaces. B Biointerfaces 73: 219-223

Jo, Y.K., Kim, B.H. and Jung, G. (2009). Antifungal activity of silver ions and nanoparticles on phytopathogenic fungi. Plant Diseases 93: 1037-1043.

Kasprowicz MJ, Kozioł M, Gorczyca A (2010) the effect of silver nanoparticles on phytopathogenic spores of Fusarium culmorum. Canadian Journal of Microbiology 56(3):247-253

Kaviya, S., Santhanalakshmia, J., Viswanathan, B., Muthumary, J. and Srinivasan K. (2011).Biosynthesis of silver nanoparticles using citrus sinensis peel extract and its antibacterial activity. Spectrochimica Acta Part A: Molecular and Biomolecular Spectroscopy. 79:594598.

Kim, S.J., Kuk, E., Yu, N.K., Kim, H.J., Park, J.S., Lee, J.H., Kim, H.S., Park, K.Y., Park, H.Y., Hwang, Y.C., Kim, K.Y., Lee, S.Y., Jeoang, H.D. and Cho, H.M. (2007). Antimicrobial effects of silver nanoparticles. Nanomedicine: Nanotechnology, Biology and Medicine 3(1): 95-101.

Kim, W.S., Jung, H.J., Lamsal, K., Kim, S.Y., Min, S.J. and Lee, S.Y. (2012). Antifungal effects of Silver Nanoparticles (AgNPs) against various plant pathogenic fungi. Mycobiology 40(1): 53-58.

Klaus, T.J., R., Olsson, E.and Granqvist, C.Gr.(1999) Silver-based crystalline nanoparticles, microbially fabricated. Proceedings of National Academy of Sciences USA96: 13611-13614. 31.

Krishnaraj, C; Ramachandran, R; Mohan, K; Kalaichelvan, P.T; (2012). Optimization for rapid synthesis of silver nanoparticles and its effect on phytopathogenic fungi. Spectrochimica Acta Part A: Molecular and Biomolecular Spectroscopy. 93:9599.

Lamsal, K., Kim, W.S., Jung, H.J., Kim, S.Y., Kim, S.K. and Lee, S.Y. (2011). Inhibition effects of silver nanoparticles against powdery mildews on cucumber and pumpkin. Mycobiology 39(1): 26-32.

Liu, P.Z., (2009) Silver nanoparticle supported on halloysite nanotubes catalyzed reduction of 4-nitrophenol (4-NP). Applied Surface Science225: 3989-3993.

Lukman AI, Gong B, Marjo CE, Roessner U and Harris AT. Facile synthesis, stabilization, and anti-bacterial performance of discrete $\mathrm{Ag}$ nanoparticles using Medicago sativa seed exudates. Journal of Colloid and Interface Science. 2011; 353:433-444.

Mohanpuria, P., Rana, K.N. and Yadav, S.K. (2008). Biosynthesis of nanoparticles: technological concepts and future 
applications. Journal of Nanoparticles

Research 10: 507-517.

Morones, J., Elechiguerra, J.L., Camacho, A., Holt, K., Kouri, J.B., Ramirez, J.T. and Yacaman, M.J. (2005). The bactericidal effect of silver nanoparticles. Nanotechnology 16: 2346-2353

Moussa, S.H., Tayel, A.A., Alsohim, A.S. and Abdallah, R.R. (2013) Botryticidal activity of nanosized silver-chitosan composite and its application for the control of gray mold in strawberry. Journal of Food Science 78(10): 589-594

NAAS 2013. Nanotechnology in Agriculture: Scope and Current Relevance. Policy Paper No. 63, National Academy of Agricultural Sciences, New Delhi: 20 p.

Nel, A., Xia, T., Madler, L. and Li, N. (2003). Toxic potential of materials at the nano level. Science 311: 622-627.

Park, H.J., Kim, S.H., Kim, S.J.and Choi, S.H. (2006) A new composition of nanosized silica-silver for control of various plant diseases. Plant Pathology Journal 22:295302

Philip D (2011)Mangifera indica leaf-assisted biosynthesis of well-dispersed silver nanoparticles. Spectrochimica Acta Part A: Molecular and Biomolecular Spectroscopy. 78:327-331

Prathna, T.C., Chandrasekaran, N., Raichur, A.M and Mukherjee, A. (2011) Kinetic evolution studies of silver nanoparticles in a bio-based green synthesis process. Colloids and Surfaces A: Physicochemical and Engineering Aspects. 377:212-216.
Ramya, M.S.S. (2012) Green Synthesis of Silver Nanoparticles. International Journal of Pharmacology Medicine and Biological Sciences 1.20-25

Sahu, N., Soni, D., Chandrashekhar, B., Sarangi, B.K., Satpute, D and Pandey, R.A.(2012) Synthesis and characterization of silver nanoparticles using Cynodon dactylon leaves and assessment of their antibacterial activity. Bioprocess Biosystematics Engineering.2012; DOI 10.1007/s00449012-0841-y

Senapati, S., (2005) Biosynthesis and immobilization of nanoparticles and their applications. University of pune, India.

Usha, R. P. and Rajasekharreddy P. (20101) Green synthesis of silver-protein (coreshell) nanoparticles using Piper betle L. leaf extract and its ecotoxicological studies on Daphnia magna. Colloids and Surfaces A: Physicochemical and Engineering Aspects. 389:188-194

Vaidyanathan, R., Gopalram, S., Kalishwaralal, K., Deepak, V., Pandian, S.R. and Gurunathan, S. (2010). Enhanced silver nanoparticle synthesis by optimization of nitrate reductase activity. Colloids Surfaces B Biointerfaces 75: 335-341.

WHO (2002) Silver and silver compounds: Environmental aspects (Concise International Chemical Assesment Document; 44Website: www.WHO.int/ipcs.

\section{How to cite this article:}

Pranab Dutta and Kaman, P.K. 2017. Nanocentric Plant Health Management with Special Reference to Silver. Int.J.Curr.Microbiol.App.Sci. 6(6): 2821-2830. doi: https://doi.org/10.20546/ijcmas.2017.606.336 